\title{
ANALISIS MISKONSEPSI SISWA PADA MATERI GERAK LURUS
}

\author{
Ni Wayan Diana Putri, Supriyatman, dan Sahrul Saehana
}

\author{
Jurusan Pendidikan MIPA \\ Fakultas Keguruan dan IImu Pendidikan Universitas Tadulako Palu
}

\begin{abstract}
Abstrak - Penelitian ini menggunakan pendekatan deksriptif kualitatif yang bertujuan untuk mengetahui miskonsepsi siswa kelas XI IPA 3 di SMA Negeri 5 Palu tentang gerak lurus. Penelitian ini dilakukan di SMA Negeri 5 Palu. Subyek penelitian adalah siswa XI IPA 3 yang terdiri dari 30 siswa. Instrumen yang di gunakan adalah tes pilihan ganda beralasan yang disertai dengan tingkat keyakinan dalam menjawab soal (Three-tier diagnostic test) berjumlah 18 butir soal. Hasil penelitian menunjukan bahwa tingkat miskonsepsi siswa dengan menggunakan Three-tier diagnostic test tergolong tinggi dengan rata-rata persentase $52,78 \%$ bila dibandingkan dengan jumlah rata-rata siswa yang tidak paham konsep yang mencapai $37,04 \%$ dan jumlah rata-rata siswa yang paham konsep mencapai 10,18\%. Miskonsepsi disebabkan karena jawaban sudah sesuai dengan konsep ilmiah namun responden tidak yakin dengan jawaban dan ada beberapa responden hanya menerka jawaban serta tidak yakin dengan jawaban. Miskonsepsi dominan pada konsep tentang kecepatan lebih besar dan kecepatan paling besar.
\end{abstract}

Kata Kunci : miskonsepsi, gerak lurus, three-tier diagnostic test

\section{PENDAHULUAN}

Rohmatin [1] mengatakan bahwa salah satu penyebab rendahnya peringkat pendidikan di Indonesia dari beberapa negara yang diteliti adalah tingkat kualitas pendidikan. Kualitas pendidik yang kurang baik berdampak pada rendahnya pemahaman siswa terhadap konsep. Pemahaman terhadap konsep yang kurang dikarenakan dalam proses pembelajaran siswa kurang didukung untuk mengembangkan kemampuan berfikir dan membangun pemahaman konsepnya.

Sebagian besar sekolah saat ini menunjukkan hasil belajar siswa pada pelajaran fisika dengan perolehan yang tidak memuaskan dan perlu mendapatkan perhatian lebih dari semua pihak yang terkait. Profil ini dapat dilihat dari hasil-hasil ujian nasional siswa SMP maupun SMA pada setiap tahunnya yang menunjukan banyaknya siswa yang memperoleh nilai yang tidak memuaskan pada mata pelajaran fisika [2].

Masalah miskonsepsi dalam berbagai bidang sains terutama fisika telah lama dan banyak diungkap oleh peneliti-peneliti dari berbagai tempat [3]. Hal ini disebabkan oleh miskonsepsi merupakan permasalahan yang cukup serius menyangkut kesuksesan dalam pembelajaran fisika. Miskonsepsi terhadap suatu konsep yang dialami siswa dapat menghambat siswa tersebut dalam mempelajari materi fisika yang baru. Dampaknya, pemahaman konsep siswa menjadi lemah [4].

Penyebab dari resistensinya sebuah miskonsepsi karena setiap orang membangun pengetahuan persis dengan pengalamannya. Sekali kita telah membangun pengetahuan yang salah, maka tidak mudah untuk memberi tahu bahwa hal tersebut salah dengan jalan hanya memberi tahu untuk mengubah miskonsepsi
itu.Terlebih bila miskonsepsi itu dapat membantu memecahkan persoalan tertentu dalam kehidupan sehari-hari [5].

Pemahaman siswa terhadap fisika akan terlihat dari pemberian evaluasi terhadap materi yang telah diajarkan, yaitu jawaban yang diberikan oleh siswa menunjukan pemahaman siswa itu sendiri. Apakah siswa menjawab sesuai dengan konsep secara ilmiah atau hanya sekedar menjawab, tidak menerapkan ide-ide atau pengetahuan yang ilmiah tetapi malah menekankan pada tafsiran pengetahuan yang keliru. Disinilah peran guru sangat diharapkan dalam pembuatan tes evaluasi tersebut agar pemahaman siswa benar terukur dan ilmiah [6].

Penelitian sebelumnya menunjukan bahwa tingkat miskonsepsi pada siswa kelas X SMA di Kota Palu cukup serius[7]. Hasil identifikasi pada enam SMA di Kota Palu dengan tes diagnostik diketahui bahwa rata-rata miskonsepsi sebesar $49,44 \%$. Bahkan siswa memiliki pengetahuan yang kurang serta menjawab pertanyaan dengan asalasalan (menebak) juga cukup signifikan, masingmasing sebesar $30,46 \%$ dan $7,60 \%$. Cukup mengejutkan bahwa siswa memiliki pemahaman konsep benar hanya sebesar $12,51 \%$. Hasil studi pendahuluan juga mengungkapkan bahwa konsep mikanika yang mengalami miskonsepsi,yaitu : gerak lurus beraturan,gerak lurus berubah beraturan,gerak melingkar,hukum newton dan perpaduan gerak [7].

Penelitian sebelumnya juga menyimpulkan bahwa rata-rata siswa yang mengalami miskonsepsi terhadap konsep-konsep fisika sangat tinggi. Salah satu penyebabnya adalah para siswa hanya banyak menghafal rumus-rumus fisika tanpa menanamkan pemahaman konsep rumus tersebut [8].

Perbedaan penelitian ini dengan penelitian sebelumnya terletak pada materi pembelajaran yang digunakan yaitu penelitian sebelumnya 
mencangkup seluruh materi kinematika sedangkan penelitian ini fokus pada materi gerak lurus dan tempat penelitiannya juga berbeda.

Peneliti berinisiatif untuk melakukan penelitian dengan menggunakan tes pilihan ganda beralasan berkeyakinan dan tes wawancara untuk mengetahui penguasaan dan keyakinan siswa dalam memahami konsep gerak lurus. Peneliti mengambil materi gerak lurus dengan alasan sering kita jumpai disekitar kita.

Adapun penelitian ini bertujuan untuk mengetahui miskonsepsi siswa kelas XI SMA Negeri 5 Palu pada materi gerak lurus. Manfaatnya dapat menjadi alternatif penelitian di bidang pendidikan fisika, sebab penelitian kualitatif masih sangat terbatas.

Miskonsepsi yang ada selanjutnya dikaji dan diteliti sehingga akan teridentifikasi sumber miskonsepsi siswa, untuk memperbaiki miskonsepsinya. Jika tidak ditelaah miskonsepsi yang dilakukan sebelumnya, maka akan sulit untuk memperbaiki sehingga analisis miskonsepsi siswa pada materi gerak lurus menjadi sangat penting.

\section{METODE PENELITIAN}

Penelitian ini merupakan penelitian kualitatif yang datanya berupa fakta-fakta yang ada, sehingga dalam penelitian ini digunakan pendekatan deskriptif kualitatif.Jenis penelitian yang digunakan dalam penelitian ini adalah studi kasus[9].Artinya penelitian ini hanya menganalisis miskonsepsisiswa melalui penggunaan three-tier diagnostic testtentang gerak lurus.Responden dalam penelitian ini berjumlah 30 orang. Responden tersebut diberikan tes pilihan ganda beralasan yang disertai dengan tingkat keyakinannya (three-tier diagnostic test) untuk mengetahui tingkat miskonsepsi yang dimiliki siswa terhadap materi gerak lurus.

Analisis data yang digunakan pada penelitian ini berdasarkan pada jawaban siswa dari tes yang diberikan. Alasan dan tingkat keyakinan yang diberikan oleh siswa dianalisis dan disesuaikan dengan pilihan jawaban yang dipilih untuk menentukan konsepsi yang dimiliki oleh siswa.

Pedoman untuk menentukan konsepsi siswa dibuat dalam bentuk tabel yang berisidua bagian yaitu kolom kategori interpretasi dan kolom tipe respons. Pada kolom tipe respons terbagi menjadi tiga bagian yaitu kolom jawaban, kolom alasan, dan kolom tingkat keyakinan [9].

TABEL 1. INTERPRETASI HASIL THREE-TIER DIAGNOSTIC TEST. [10]

\begin{tabular}{ccccccc}
\hline \multirow{2}{*}{ Kategori } & \multicolumn{5}{c}{ Tipe Respons } \\
\cline { 2 - 7 } & Jawab & $\mathrm{S}$ & Alasan & $\mathrm{S}$ & Keyakinan & $\mathrm{S}$ \\
\hline Memahami & benar & 1 & benar & 1 & Yakin & 1 \\
\hline \multirow{3}{*}{ Tidak Memahami } & benar & 1 & benar & 1 & tidak yakin & 0 \\
\cline { 2 - 7 } & benar & 1 & salah & 0 & tidak yakin & 0 \\
\cline { 2 - 7 } & salah & 0 & benar & 1 & tidak yakin & 0 \\
\cline { 2 - 7 } & salah & 0 & salah & 0 & tidak yakin & 0 \\
\hline \multirow{3}{*}{ Miskonsepsi } & salah & 0 & salah & 0 & Yakin & 1 \\
\cline { 2 - 6 } & salah & 0 & benar & 1 & Yakin & 1 \\
\cline { 2 - 6 } & benar & 0 & salah & 0 & Yakin & 1 \\
\hline
\end{tabular}

\section{HASIL DAN PEMBAHASAN}

\section{Hasil Penelitian}

Penelitian ini bertujuan untuk mengetahui miskonsepsi siswa kelas XI SMA Negeri 5 Palu pada materi gerak lurus. Responden dalam penelitian ini adalah siswa kelas XI IPA 3. Instrumen yang digunakan dalam penelitian ini yaitu soal pilihan ganda beralasan.
Hasil analisis jawaban responden mengenai tes miskonsepsi pada konsep gerak lurus yang diujikan pada siswa XI IPA 3, diperoleh nilai rata-rata $10,18 \%$ siswa yang paham konsep, $37,04 \%$ siswa tidak paham konsep, dan $52,78 \%$ siswa yang mengalami miskonsepsi. Tingkat persentase ratarata konsepsi siswa terhadap gerak lurus dapat dilihat pada Gambar 1.

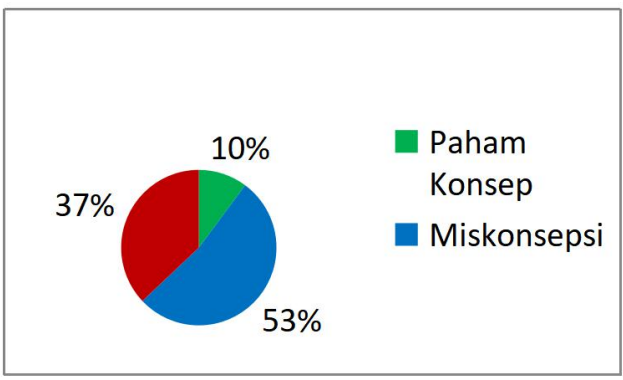

Gbr 1.Persentase konsepsi siswa terhadap materi gerak lurus. 
Persentase jumlah siswa yang mengalami miskonsepsi dan tidak paham konsep cukup banyak dibandingkan yang paham konsep.Miskonsepsi yang dialami siswa pada gerak lurus umumnya variatif untuk setiap soal.Berikut profil miskonsepsi mahasiswa dari beberapa konsep yang memiliki tingkat persentase tertinggi.

TABEL 2. ANALISIS KONSEPSI SISWA TERHADAP MATERI GERAK LURUS UNTUK SETIAP SOAL.

\begin{tabular}{|c|c|c|c|c|}
\hline No & Indikator & $\mathrm{P} \quad(\%)$ & $\mathrm{TP}(\%)$ & M (\%) \\
\hline \multirow{2}{*}{1} & \multirow{2}{*}{ Jarak tempuh } & 26,67 & 13,33 & 60,00 \\
\hline & & 3,33 & 33,33 & 63,33 \\
\hline \multirow{4}{*}{2} & \multirow{4}{*}{ Kecepatan dan tempuh } & 6,67 & 36,67 & 56,67 \\
\hline & & 0 & 33,33 & 66,67 \\
\hline & & 0 & 40,00 & 60,00 \\
\hline & & 10,00 & 60,00 & 30,00 \\
\hline \multirow[t]{4}{*}{3} & \multirow[t]{4}{*}{ Grafik pada GLB } & 0 & 50,00 & 50,00 \\
\hline & & 0 & 50,00 & 50,00 \\
\hline & & 3,33 & 23,33 & 73,33 \\
\hline & & 3,33 & 23,33 & 73,33 \\
\hline \multirow[t]{3}{*}{4} & \multirow[t]{3}{*}{ Grafik pada percepatan } & 30,00 & 30,00 & 40,00 \\
\hline & & 6,67 & 50,00 & 43,33 \\
\hline & & 10,00 & 30,00 & 60,00 \\
\hline \multirow[t]{3}{*}{5} & \multirow[t]{3}{*}{ Grafik pada GLBB } & 0 & 50,00 & 50,00 \\
\hline & & 0 & 53,33 & 46.67 \\
\hline & & 3,33 & 43,33 & 53,33 \\
\hline \multirow[t]{3}{*}{6} & Posisi benda dan keceptan & 80,00 & 3,33 & 16,67 \\
\hline & & 0 & 43,33 & 56,67 \\
\hline & Rata-rata & 10,18 & 37,04 & 52,78 \\
\hline
\end{tabular}

Ket : $\mathrm{P}=$ paham konsep, $\mathrm{TP}=$ tidak paham konsep,M= miskonsepsi

\section{Pembahasan}

Hasil penelitian menyatakan bahwa siswa yang mengalami miskonsepsi pada konsep gerak lurus adalah $52,78 \%$. Jumlah persentase ini menyatakan bahwa miskonsepsi pada siswa berada dalam kategori yang tinggi.

Dari 18 nomor soal yang diujikan dengan konsep yang berbeda-beda ada 13 soal yang dapat menggali miskonsepsi siswa dengan nilai tingkat persentase tinggi yang berkisar antara $50,00 \%-73,33 \%$. Soal-soal tersebut diantaranya tentang konsep jarak, perpindahan, kecepatan, kelajuan, mengidentifikasi grafik v-t pada GLB, menunjukan grafik $x$-t pada GLB, menganalisis gafik v-t pada jarak, menganalisis grafik $x$-t pada kecepatan, mengidentifikasi grafik $v$ - $t$ pada kecepatan, menganalisis grafik a-t pada GLBB, menganalisis grafik v-t pada GLBB, menentukan posisi benda pada GLB, dan menghitung kecepatan GLBB.Dari beberapa soal tersebut yang termasuk dalam kategori miskonsepsi dengan tingkat persentase tertinggi mencapai $73,33 \%$ yaitu konsep tentang kecepatan lebih besar dan kecepatan paling besar.

Deskripsi kategori miskonsepsi tertinggi dari soal yaitu hasil analisis jawaban responden mengenai konsep menganalisis grafik $x-t$ pada kecepatan lebih besar. Dengan soal, Angga dan dito mengendarai sepeda motor yang berbeda. Manakah grafik yang menggambarkan keadaan gerak dito lebih cepat di banding angga ? (Angga : I dan Dito : II )
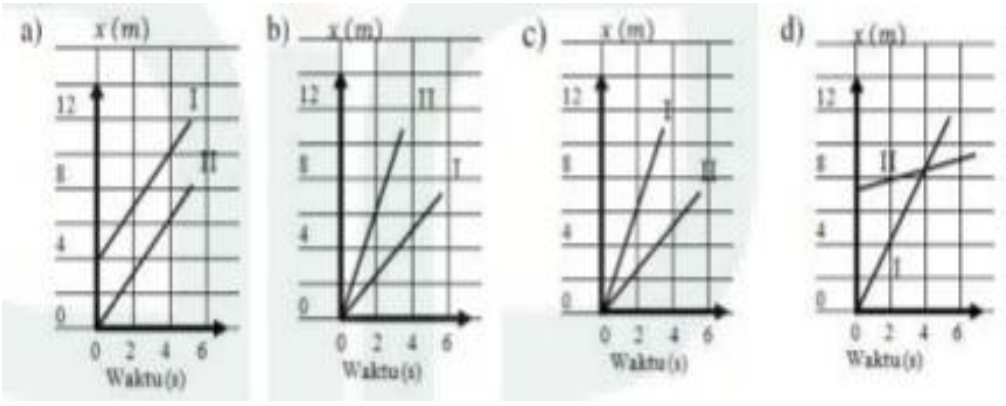

Gbr 2. Pilihan jawaban 
Jawaban yang benar yaitu B dengan alasan Angga memiliki jarak tempuh yang lebih jauh di banding Dito dalam waktu yang sama. Adapun yang menyebabkan miskonsepsi yaitu beberapa responden menjawab dengan benar tetapi memberi alasan salah dan tidak yakin. Analisis soal bisa dilihat pada Tabel 1.

Sebuah benda bergerak pada lintasan lurus dengan grafik kecepatan terhadap waktu ditunjukan pada gambar di bawah ini. Grafik tersebut telah di bagi atas 5 bagian ( $A, B, C, D$, dan $E$ )

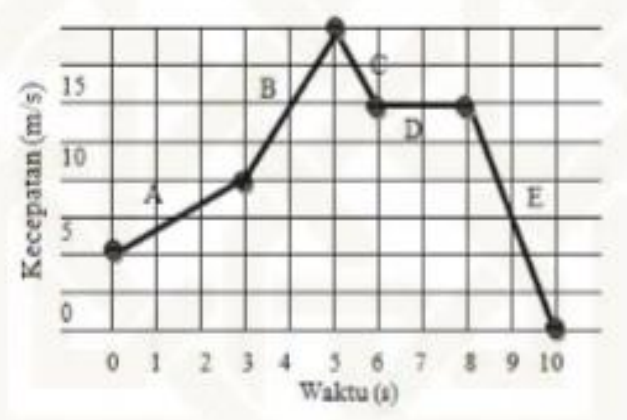

Gbr 3. Grafik soal

Hasil analisis jawaban responden mengenai konsep mengidentifikasi grafik v-t pada kecepatan paling besar,diperoleh persentase siswa yang mengalami miskonsepsi yaitu $73,33 \%$. Jawaban yang benar adalah pilihan jawaban D. Pada titik $\mathrm{E}$ dan titik $\mathrm{C}$ dengan alasan keduanya memiliki besar percepatan terbesar tetapi berbeda arah geraknya. Adapun yang menyebabkan miskonsepsi yaitu beberapa responden menjawab hanya dengan menebak dan ada beberapa jawaban responden sudah sesuai dengan konsep ilmiah namun responden tidak yakin dengan jawabannya. Analisis soal bisa dilihat pada Tabel 1.

Deskripsi kategori miskonsepsi terendah diperoleh persentase siswa yang mengalami miskonsepsi yaitu $16,67 \%$. Analisis jawaban responden dengan soal, selembar kertas di letakan di atas meja.Sebuah koin diletakan di atas kertas,kemudian kertas di tarik dengan sangat cepat. Apa yang terjadi dengan koin tersebut?

a. Bergerak kearah tarikan kertas

b. Bergerak berlawanan arah tarikan

c. Bergerak ke samping kanan

d. Tetap diam

Jawaban yang benar yaitu $D$ dengan alasan pada awalnya koin diam diatas kertas, kemudian kertas di tarik dengan sangat cepat maka koin akan mempertahankan keadaan diam. Adapun yang menyebabkan miskonsepsi yaitu beberapa respondensudah sesuai dengan konsep ilmiah namun responden tidak yakin dengan jawabannya. Analisis soal bisa dilihat pada Tabel 1.

Jika dibandingkan dengan penelitian sebelumnya [1], [7], penelitian ini memiliki persentase miskonsepsi yang lebih tinggi.

\section{KESIMPULAN DAN SARAN}

\section{Kesimpulan}

Berdasarkan hasil penelitian menunjukkan bahwa tingkat miskonsepsi siswa SMA Negeri 5 Palu dengan menggunakan Three Tier Diagnostic Test masih tergolong tinggi dengan rata-rata persentase sebesar $52,78 \%$ bila dibandingkan dengan jumlah rata-rata siswa yang tidak paham konsep yang mencapai 37,04\% dan jumlah ratarata siswa yang paham konsep mencapai $10,18 \%$.

\section{Saran}

Berdasarkan kesimpulan di atas maka saran yang dapat diberikan pada penelitian ini adalah:

1. Pengajar diharapkan dalam menjelaskan konsep fisika khususnya konsep Gerak Lurus tidak hanya berfokus dalam persoalan matematis, namun harus menjelaskan konsep secara fisis dan mengaitkan konsep fisika dengan fenomena-fenomena dalam kehidupan sehari-hari.

2. Membiasakan siswa atau merangsang siswa untuk mampu menganalisis soal sebelum melakukan pemecahan masalah agar siswa dapat memahami permasalahan pada soal.

3. Penelitian ini hanya membahas mengenai miskonsepsi belum meneliti mengenai faktorfaktor yang menyebabkan terjadinya miskonsepsi. Untuk itu, perlu dilakukan penelitian lebih lanjut untuk menentukan faktor-faktor penyebab terjadinya miskonsepsi dikalangan siswa.

\section{DAFTAR PUSTAKA}

[1] U.N.,Rohmatin. "Pengembangan Instrumen Three Tier Test Berbasis Representasi Grafik Untuk Mengetahui Miskonsepsi Siswa Pada Materi Gerak Lurus".Yogyakarta :Skripsi UIN Sunan Kalijaga Indonesia.Diterbitkan 2016.

[2] M.,Halomoan. "Analisis Konsepsi Guru Mata Pelajaran Fisika Madrasah Aliyah Terhadap Konsep Gaya Pada Benda Diam dan Bergerak". 
[Online].Tersedia:http://sumut.kemenag.go.id /jurnal-pendidikan.pdf,. [15 april 2018]. 2008.

[3] S.,Bayraktar. "Misconceptions of Tur-kish Pre-Service Teachers about Force and Motion". International Journal of Science and Mathematics Education. Vol (7), pp 273291.grantnumberCAT140. Juli 2009.

[4] D,.Hammer. "More than Misconceptions: Multiple Perspectives on Student Knowledge and Reasoning, and An Appropriate Role for Education Research". American Journal of Physics, 64, (10),1-3. Maret 1996.

[5] F.,Maftuhah. "Identifikasi Miskonsepsi dalam Konsep Dinamika Partikel Siswa Kelas XI SMA Negeri 2 Sukoharjo".Surakarta: Skripsi Fakultas Keguruan dan IImu Pendidikan Universitas Sebelas Maret. Tidak diterbitkan. 2011.

[6] D.D.,Syahruldan S.,Woro."Identifikasi miskonsepsi dan penyebab miskonsepsi siswa dengan trhee-tier diagnostic test pada materi dinamika rotasi".Jurnal Inovasi Pendidikan Fisika. Vol (04), (03), pp 67-70. Januari 2015.
[7] S.,Saehana. "Pengembangan Simulasi Komputer Dalam Model Pembelajaran Kooperatif Untuk Meminimalisir Miskonsepsi Fisika Pada Siswa SMA Di Kota Palu. Laporan Penelitian Pada Lembaga Penelitian Universitas Tadulako: tidak diterbitkan. 2006.

[8] N.,Maharta. "Analisis Miskonsepsi Fisika Siswa SMA Di Bandar Lampung. Jurnal FKIP Fisika Universitas Lampung". [Online]. Tersedia:

http:/id.scribd.com/doc/41470237/JurnalAnalisis-Miskonsepsi-Fisika. [15 April 2018].

[9] S.,L.,Handayani,A.,Rusilowati, danSugianto. "Mengembangkan tes diagnostik pilihan ganda tiga tingkat sebagai alat evaluasi miskonsepsi materi optik". Artikel Seminar nasional evaluasi pendidikan. 2014.

[10] M.F.,Wiyono, Sugianto danE.,Yulianti."Identifikasi Hasil Analisis Miskonsepsi Gerak Menggunakan Instrumen Diagnostik Three Tier Pada Siswa SMP".Jurnal Penelitian Fisika \& Aplikasinya.Vol (6), pp 61-69. April 2016. 